\title{
Investigating the nature of and relation between masculinity and religiosity and/or spirituality in a postcolonial and post-apartheid South Africa
}

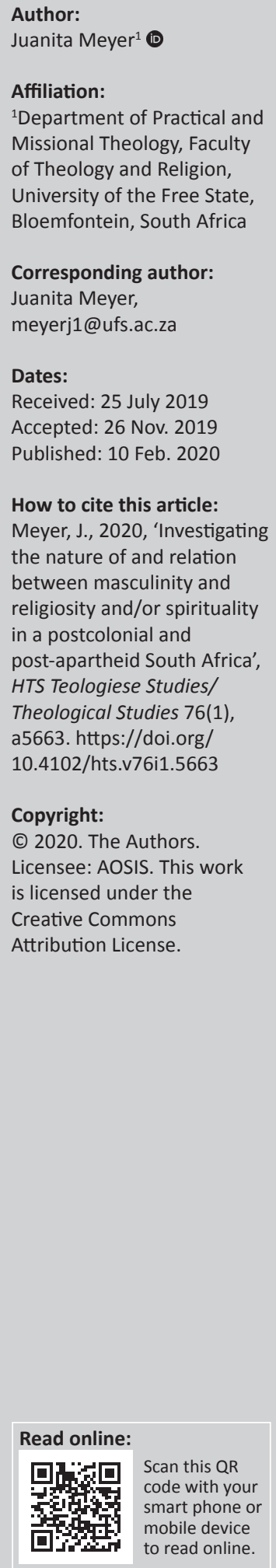

Author:

Affiliation

${ }^{1}$ Department of Practical and Missional Theology, Faculty of Theology and Religion, University of the Free State, Bloemfontein, South Afric

\section{Juanita Meyer}

Dates:

Received: 25 July 2019

Accepted: 26 Nov. 2019

Published: 10 Feb. 2020 the nature of and relation between masculinity and religiosity and/or spirituality in a postcolonial and HTS Teologiese Studies/ Theological Studies 76(1), a5663. https://doi.org/

Copyright: Licensee: AOSIS. This work is licensed under the creative Commons mobile device to read online.
This article narrates the researcher's intention in using a mixed methodology for investigating the correlation between two key research concepts that form part of a larger research study. The larger study aims to reflect on how South African men understand their masculine role from and within their specific religion/spirituality by measuring the nature of the relationship between the constructs of masculine ideology and religious orientation in the development of a male gender identity. Subsequently, the first level of exploration includes the distribution of two inventory scales to a wide selection of men in South Africa for determining the nature and degree of correlation between the two concepts of 'masculinity' and 'religiosity/spirituality' from this specific sample of men. The research question to be answered is as follows: is there a correlation between the results of the two inventory scales (Masculine Attitude Norms Inventory II/Masculinities Representations Inventory [MANI II/MRI] and Religious Orientation Scale - Revised [I/E-Revised]) which measures male attitude norms, on the one hand, and religious orientation, on the other hand, of a selected sample of South African men? This question is answered through the administration of two widely validated and reliable inventory scales aimed at measuring male ideology and representations and religious orientation, respectively. Consequently, the researcher aims to motivate her choice of employing these scales before a post-foundational practical theological and narrative approach to research is used in 'thickening' the discourses resulting from these inventories, and narrates what she aims to achieve through the employment of these specific methodologies. Therefore, this article does not aim to narrate any research findings but forms part of Phase 1 of the larger research project delineated into different phases. The researcher concludes with a suggested research methodology, which aims at the decolonisation of the constructs of masculinity and religiosity and/or spirituality in the specific context of postcolonial and post-apartheid South Africa.

Keywords: masculinity and religiosity and/or spirituality; MRI and I/E-revised; South Africa; post-apartheid; postcolonial.

\section{Introduction}

This article narrates the researcher's intention in using a mixed methodology to investigate the correlation between two key research concepts forming part of a larger research study. The larger study aims to reflect on how South African men understand their masculine role from and within their specific religion/spirituality by measuring the nature of the relationship between the constructs of masculine ideology and religious orientation, in the development of a male gender identity. Subsequently, the first level of exploration includes the distribution of two inventory scales to a wide selection of men in South Africa in determining the nature and degree of correlation between the two concepts of 'masculinity' and 'religiosity/spirituality' (R/S) from this specific sample of men. The research question to be answered is as follows: is there a correlation between the results of the two inventory scales (Masculine Attitude Norms Inventory II/Masculinities Representations Inventory [MANI II/MRI] and Religious Orientation Scale Revised [I/E-Revised]) which measures male attitude norms, on the one hand, and religious orientation, on the other hand, of a selected sample of South African men? This question is answered through administration of two widely validated and reliable inventory scales aimed at measuring male ideology and representations (cf. Luyt 2005, 2015, 2017) and religious orientation (cf. Gorsuch \& McPherson 1989) respectively. Through this article, the researcher motivates her choice of employing these scales before a post-foundational practical theological and narrative approach to research is used in 'thickening' the discourses resulting from these inventories, and narrates what she aims to achieve through the employment of these specific 
methodologies. Therefore, this article does not aim to narrate any research findings but forms part of Phase 1 of the larger research project delineated into different phases.

The researcher concludes with a suggested research methodology which aims at the decolonisation of the constructs of masculinity and religiosity and/or spirituality in the specific context of postcolonial and post-apartheid South Africa.

\section{Problem statement}

According to Statistics South Africa (StatsSA) (Maluleke 2018:1, 6), the National Development Plan (NDP) aims to liberate South African women and children by advocating their rights to walk freely in the streets and play safely in open spaces by 2030.

This plan is created in direct response to the dire statistics regarding the safety of women and children in South Africa. The 'Crime against women in South Africa' (Maluleke 2018:7) report refers to the World Health Organisation (WHO), which announced that in '2000, the South African murder rate of women was more than five times the global average'. According to WHO, this rate decreased in 2015 but was still about twice as much as experienced globally. The same statistics are applied to men, and with reference to the period between 2000 and 2015, ' $[t]$ he homicide rate for men consistently stood at more than three times the rate for women' (Maluleke 2018:8), which means that although in effect violence against women in South Africa is at a distressing level, men are still more likely to be victims of murder than women. Even the more concerting fact is that women and girls in South Africa are most unsafe in the world when it comes to sexual violence in general and rape in particular (Maluleke 2018:8; cf. Bachman 1994).

Besides the overt discrimination against women, women and girls are frequent victims of less obvious forms of abuse such as emotional and psychological abuse and, as some would argue, even spiritual abuse. Bent-Goodley and Fowler (2006:282) postulate that domestic violence or emotional, psychological or spiritual abuse are often perpetuated by 'faith-based communities in overt and covert ways' (Adams \& Fortune 1995; Bell \& Mattis 2000; McClure \& Ramsay 1998; Neighbors, Musick \& Williams 1998; Raj \& Silverman 2002; Sanders 1995; West 1999; Wolff et al. 2001).

Accordingly, Bent-Goodley and Fowler (2006:283-284) state that many religious women are encouraged to remain in abusive relationships by faith leaders who justify the wife's obligation to do so from religious texts, such as the Bible. They emphasise that '... scripture may become a means of stimulating confusion and anger when it is used to manipulate and control a partner' Bent-Goodley and Fowler (2006:283-284). It is therefore clear that spirituality and religion can indeed be used as powerful mechanisms to negate, overpower and control women.
When violence against women and children is voiced, men are automatically implied as perpetrators. The report titled 'Crime against women in South Africa' (Maluleke 2018:5), however, includes statistics regarding the effect that crime has been not only on women but also on men in general. This development is significant for various reasons. Firstly, the safety of women and children cannot be effected without the help of and change occurring in men. Secondly - but not secondary inevitably, men are also negatively affected by their own actions, behaviours and subsequent consequences of these behaviours which limit their potential to form meaningful relationships with opposite sex and their own children; decrease internal resources available to them to deal with conflict constructively and ultimately reduce their capacity to experience true happiness and content in life.

South Africa can, in general, be described as a religious society where $86 \%$ of the population affiliates with Christianity (Statistics South Africa 2016:3). Despite the religious/spiritual orientation of South Africans, it is one of the countries with the highest levels of violence against women and children and violence amongst men, as seen earlier. That is why the relation or correlation between gender orientation (e.g. masculinity) and religiosity/spirituality is questioned.

\section{Background of the study}

The larger research project from which the above research question emanates focusses on the concepts of masculinity and religiosity and/or spirituality, and its relation with each other in the development of a male gender identity. This study suggests that religiosity/spirituality in South Africa relates with and informs men's notion of masculinity, their cultural values and the degree to which they are involved in both marriage and parental responsibilities. It is suggested that these constructs interact with each other in a distinct manner to produce a specific South African masculinity, which in turn informs the social construction of a 'Christian man': who should be a Christian man, and how should such a man behave. The construction of such masculinity in turn informs and aims to control femininity, and the type of feminine behaviour allowed within the religious context and sphere. Such hegemonic masculinities, described by religion, play a vital role not only in reconstructing and perpetuating certain traditional masculinities but also in constructing femininities, thereby perpetuating the cycle of power over gender and gender discourse.

This specific section of the research investigates the possible relationship between South African masculinities and religiosity/spirituality through the application of two inventory scales to a sample of South African men. As such, this exploration includes the distribution of two inventory scales to some of the male students residing at selected male hostels of the University of the Free State (UFS). Additionally, an electronic version of these questionnaires was distributed via email and through various social platforms to male acquaintances in general and male ministers in particular. 
Any male South African citizen over the age of 18 years qualified to complete the questionnaires. The aim of this method of data collection and analysis was to determine the nature and degree of correlation, if any, between the concepts of 'masculinity' and 'religiosity/spirituality' in this specific sample of men. The assumption was that the determination of the existence of a correlation, and the nature and the strength (degree) of this possible correlation, might provide a foundation upon which specific experiences could be elicited regarding the causes of this correlation. Narratives of these experiences could in turn provide insights regarding the mechanisms behind the social construction of a 'Christian man', how this construction operates in the domain of gender relations, and whether these relations could be transformed through the institutionalised church or other faith-based institutions as to better its quality and the outcomes for all persons involved.

\section{Research design Data collection}

The larger research study employs research methods mainly from a qualitative and case study research design whilst including mixed methods of inventory scale administration in a section of its data collection methodology.

Primary data collection methods (for the larger study) include interviews, artefacts, archival records, literature research, direct observations and participatory observations. This protocol, however, entails the quantitative aspect of a mixed-method research design in administering two widely validated and reliable inventory scales aimed at measuring male ideology and representations (cf. Luyt 2005, 2015, 2017) and religious orientation (cf. Gorsuch \& McPherson 1989) respectively.

\section{The Religious Orientation Scale - Revised}

Hill and Maltby (2009:41) emphasise that amongst the plethora of measuring instruments which aim at measuring religiosity and/or spirituality, Allport's (1950) original Religious Orientation Scale (ROS; Allport \& Ross 1967) is still the preferred one amongst scholars despite some criticism. In 1983, Gorsuch and Venable revised Allport's original ROS to increase the applicability of its scales in terms of educational level (Gorsuch \& McPherson 1989:348). The ROS differs from other measuring instruments in its distinction between intrinsic (I) and extrinsic (E) as motivation behind a person's religious affiliation, involvement and/or degree of spirituality. As such, a high score on the intrinsic orientation scale indicates that the practice of religion is regarded as a goal in itself, whilst measuring high on the extrinsic orientation scale indicates that religious practice is regarded as a way in which some personal or social goal could be achieved - a means to a certain end. Accordingly, a person measuring high on intrinsic motivation is regarded as the so-called 'true believer', whilst an extrinsically motivated person uses religion as an instrument (King \& Crowther 2004:86).
Jurkovic and Walker (2006:28) refer to extrinsic religiosity as the 'religion of comfort and social convention, a self-serving instrumental approach shaped to suit oneself'; and intrinsic religiosity as 'a meaning-endowing framework in terms of which all life is understood'.

The measuring instrument distributed during this research project was the Religious Orientation Scale - Revised (I-E/R) as revised by Gorsuch and McPherson (1989). This version is regarded as the best-suited measuring instrument for religious orientation, as it has been found to have strong psychometric properties (Judd 2009):

... [W]ith reliability for INT being.83 and EXT.65 (Hill 1999). The validity of the Religious Orientation Scale is generally well supported, but due to the value-laden nature of the scale, and the evolving definition of INT and EXT over time, specifically what it measures has been open to a great deal of discussion. However, given that INT is defined roughly as religion as master motive and EXT defined as a hands-off attitude towards religion, there is general validity supported across multiple studies (Burris 1999). (p. 9)

Critique regarding the ROS revolves around the object of measurement and is indicated by questions regarding what exactly it measures. The consensus is - although not unanimous - that ROS measures intrinsic and extrinsic motivation of religious beliefs and practices (Hoge 1972; Hunt \& King 1971; King \& Crowther 2004:86) as indicated by either a high or low score on the intrinsic or extrinsic scale. The possibility exists that one can fall into the middle of the continuum, not measuring high or low on either pole, with no clear interpretation of such scores. However, if intrinsic motivation indicates that a person is motivated by pure religious motives, and extrinsic people are motivated by whatever religiosity could achieve on a personal or social level (cf. King \& Crowther 2004:86-87), then this study assumes that being neutral on both scores might indicate that no strong motivation exists for being religious or spiritual at all. This assumption could, of course, be disputed and debated with the occurrence of such scores. ${ }^{1}$

This specific study hopes to witness a correlation of either intrinsic or extrinsic motivation behind religious orientation with the total scale of Masculinities Representations Inventory (MRI). The total scale of MRI comprises adding individual scores of three subscales that either indicate a strong identification with a culture's traditional ideas around masculinity or not. Individual scores on the three subscales are also of significance, as a person can identify strongly with either one of the subscales, with the exclusion of the remaining one or two subscales. The three subscales are as follows: (1) anti-effeminacy and homo-negativity; (2) dependability and success and (3) dominance and toughness.

Subsequently this study hypothesises that a positive correlation between measures on the extrinsic scale and the MRI total score might indicate that religion enforces a certain 1.No such occurrence has been observed up to date by the researcher. 
position of male power over women or non-hegemonic men (e.g. personal and social means to an end) within that specific religion and its subsequent culture. Correspondingly it might indicate that a specific religion, or body of beliefs, supports a specific notion of masculinity over a specific notion of femininity, where one expects antipathy towards homosexuality, and rigid role divisions at home and work between the sexes.

\section{Masculine Attitude Norms Inventory/Masculinities Representations Inventory}

The MRI is a revised version of the Masculine Attitude Norms Inventory I and II (MANI I and MANI II), which were developed in 2005 by Luyt to offer a multidimensional measure of masculinity ideology(ies) in South Africa. In concept, the MANI I and II were designed to evaluate the degree to which South African men internalise traditional notions of masculinity, which in turn support predominant gender scripts and subsequent power relations. These instruments are therefore in line with other instruments that measure gender ideology(ies) but revised for the South African context in being sensitive to culture and context and the manner in which these influence ideas regarding masculinity (cf. Luyt 2017:5).

In turn, the MRI was developed as the notion of 'ideology' measured by the two MANIs, and was revised and reconceptualised into the notion of 'representation'. Luyt (2017:2) proposes that this multidimensional measure of gender (re)presentation aims to measure the extent to which dominant gender representations are endorsed on a sociocultural and group level as opposed to an individual level, where it is assumed that ideologies are internalised personally and operationalised individually. In support of this, Luyt (2015) argues that the 'gender (re)presentation approach to measurement' is firmly grounded in the social constructionist appreciation that gender operates in social contexts, and should thus be understood as a social phenomenon. Conversely, an orientation approach to gender aims at measuring gender as an individual phenomenon, assuming that the operation of gender could be measured in terms of 'individual attributes, characteristics or traits' (Luyt 2017:2; cf. Thompson \& Pleck 1986). This assumption is based on the notion that differences between men and women are inevitably imbedded in physiology, and related differences in early experiences (Constantinople 1973:390; Luyt 2017:2). An ideological approach to measuring gender also focusses on the individual and the degree to which an individual internalises specific cultural notions of gender and gender roles (Luyt 2017:2; cf. Levant et al. 2007:373).

Social constructionism argues that gender is better understood as a social phenomenon, and likewise suggests a gender representation approach to measurement (Luyt 2017:2-3). A gender representation approach to measurement thus postulates that people ratify dominant gender representations in groups and that these social dynamics of representing certain notions around gender are used to reproduce the same or similar notions and to legitimise imbalanced gender relationships. This, in turn, creates 'specific gender subject positions' (Luyt 2017:3; cf. Luyt 2015:222).

According to social constructionists, gender is not something people 'have' but, rather, is something people 'do' - gender is represented in a specific manner, in a specific context, because it means something specific to them. Luyt (2017:4) emphasises that ' $p$ ] eople make sense of normative statements included in measures of gender (re)presentation in a contextually meaningful way', and that they respond in a specific context by 'doing gender'.

\section{Luyt (2017) further states:}

These responses do not reflect some internal, preformed, and stable mental state. Rather, they point toward available systems of meaning, which are shared by other group members and strategically deployed by them to make sense of their world and claim subject positions within the course of situated interaction. (p. 4)

Therefore, to understand the power of dominant discourse - or in this case, dominant gender representations - in determining how people would act within their social groups, gender should be measured on a sociocultural level. Studying gender from this perspective elucidates not only the behaviour of a specific gender but also the function of this behaviour and different positions of power that it creates as a result (Luyt 2017:4; cf. Luyt 2015).

Accordingly, a gender representation approach to measurement suggests that the relevant instrument should measure gender in terms of the following five main characteristics (Luyt 2017:3-4):

- Construct multidimensionality: An emphasis on multiple masculinities, femininities and other gender practices.

- Construct independence: A clear distinction between masculinity, femininity and other gender-related concepts.

- A focus on social or group level, as opposed to individual phenomena.

- Suitable evidence of measurement validity.

- Theoretically appropriate content. (Luyt 2015:220)

This framework in which gender representations are measured allows the examination of gender attitudes through determining the ways in which underlying dimensions are being ratified by group members. This paradigm also acknowledges that although gender constructs are often demarcated into conflicting categories, they may nevertheless share defining features (Luyt 2017:4).

\section{Data analysis}

The interpretation of individual instruments was conducted with the use of the scoring sheet applicable to each instrument. 
The correlation between the results of the two instruments was calculated by taking into account the Pearson's productmoment correlation coefficient between the two variables as were correlations between demographical data and the results of the two separate instruments.

\section{Sampling}

For the administration of the two inventory scales, specific male residents from the UFS campus were selected with the help of university's Assistant Director of Student Affairs through the purposive sampling technique, a non-probability sampling method. To increase the scope of sampling, electronic forms of these two inventory scales were uploaded on the online platform of esurveycreator.com. These surveys could be accessed as one survey through the following link: https://www.esurveycreator.com/s/74b12a3. This link was posted on various social networks of the researcher to be accessed by any voluntary participant who qualifies for participation. The participant's characteristics include any male South African citizen and over the age of 18 years. An informed consent form was also part of the e-form. Additionally, soft copy of the survey was mailed in bulk as a PDF format to various ministers on the database of the Faculty of Theology and Religion at the UFS.

\section{Religion, spirituality and masculinity}

Understanding the differences between the concepts of 'religion' and 'spirituality' seems to be complex indeed. Whilst some scholars agree that the two concepts are related and therefore indistinguishable, others propose that they should be considered separately because of their unique differences. As such, some scholars view religion as an institutionalised group activity, where affiliated members act in a specific manner, in a specific social context, guided by doctrinal and denominational specificities (cf. Fetzer Institute 1999; King \& Crowther 2004:84). Other scholars, in turn, view the concepts related in terms of its influence on the development of the other. Accordingly, some state that spiritual practices form an integral part of religion and those subsequent religious practices might nurture spiritual growth (cf. Armstrong \& Crowther 2002; King \& Crowther 2004:84). It is also possible - some postulate - that one can affiliate with a specific religion without developing a personal connection with God or a Higher Being. According to Allport and Ross (1967), the original developers of ROS, such a person measures high on the extrinsic scale, which indicates an extrinsic orientation to religion and the probability that religion is a means to a specific end on personal and social levels (King \& Crowther 2004:84).

For the purpose of this study (and as used in this article), the following definition of religiosity and spirituality ${ }^{2}$ is utilised:

Religion is an organized system of beliefs, practices, rituals and symbols designed (a) to facilitate closeness to the sacred or transcendent (God, higher power, or ultimate truth/reality), and (b) to foster an understanding of one's relation and responsibility to others in living together in a community. Spirituality is the personal quest for understanding answers to ultimate questions about life, about meaning, and about relationship to the sacred or transcendent, which may (or may not) lead to or arise from the development of religious rituals and the formation of community. (Koenig, McCullough \& Larson 2000:18)

In adopting the above definition, the researcher acknowledges that this research project views masculinity as it is influenced or supported not only by institutionalised religion (and subsequent doctrines and theologies) but also its development from a specific spirituality which might have emerged from a specific religious affiliation and the relationships forged from this social context. It is assumed that notions of gender roles and responsibilities would have developed from traditions communicated from and within a faith-based institution (based on specific theologies), and integrated into a specific culture and extended to gender operations within the familial home and, at times, the work place. Even though participants might not be active 'churchgoers', religion and subsequent spiritualities tend to be integrated within sociocultural contexts and subsequent gender prescriptions, irrelevant of the degree of religiosity.

Another issue that influences the study of masculinity and religiosity and/or spirituality is research that has shown the tendency of women to be more religious than men (cf. Argyle \& Beit-Hallahmi 1975; DeVaus \& McAllister 1987; Francis \& Wilcox 1996; Jurkovic \& Walker 2006:29; Paloma \& Gallup 1991). Thompson (1991) suggested that these differences are because of arguments regarding gender-role socialisation whereby boys are encouraged to be less feminine. As some level of femininity seems to be a prerequisite in the degree of religiosity or spirituality that a person might reveal (see studies conducted by Ekhardt and Goldsmith (1984) and Francis (1991) with regard to clergymen that possess feminine qualities; and Francis and Wilcox (1996), who found that both feminine men and women tend to be more), socialisation that favours masculine qualities over feminine qualities for men results in men being less religious, at the very least on an intrinsic level (cf. Jurkovic \& Walker 2006:28-29). Erikson (1958, 1969) also confirmed these findings by postulating that 'the feminine mode is the basis of internalised religious experience and expression' (Jurkovic \& Walker 2006:29).

Because of the finding that men globally tend to be less religious than women, scholars have investigated the causes of this phenomenon. One such hypothesis is that of the above-mentioned gender-role socialisation theory, which - as mentioned - suggests that boys are socialised in being antifeminine. This enquiry into the fear of femininity as taught through socialisation has resulted in the three subscales of MRI as mentioned above in the section 'The Religious Orientation Scale - Revised'. This relates in some way or the other to the manner in which boys are raised to be much 
different than girls, or not feminine-like. One can therefore argue that being a successful person - a person one's family can depend upon - is not a feminine attribute; and likewise being dominant and tough is also a way of not being feminine (according to commonly [western] accepted definitions of being feminine).

Subsequently the gender-role strain theory developed by Mahalik and Lagan (2001) provides a heuristic paradigm which argues that the very nature of the masculine socialisation process is to restrict men from internalising any feminine norms, thereby encouraging the internalisation of stereotypical societal male norms and ideals, however ambiguous and unachievable these might be (cf. Jurkovic \& Walker 2006:29; Pleck 1981, 1995). These findings are supported by studies conducted by O'Neil in 1981 and 1990. O'Neil (1990:25) postulates that 'rigid, sexist, or restrictive gender roles learned during socialization result in personal restrictions, devaluation, or violation of others or self'. Therefore, the gender-role conflict theory, emanating from the gender-role strain theory, hypothesises that discourses disseminated through traditional male socialisation lead to unrealistic expectations and the fear of acting in unacceptable feminine ways (cf. O’Neil 1981, 1982). In turn, a conflict exists within men whereby they have to ensure that their conduct is directed and informed by stereotypical male behaviour for the fear of being judged too feminine (cf. Jurkovic \& Walker 2006:29). As a result of these findings, the MRI developed a specific subscale that measures the degree of femininity.

If conduct does not conform to that expected of by a specific culture/group, then men might experience, as described by Eisler and Skidmore (1987), masculine gender-role stress (MGRS). As insinuated by the term, this is a negative cognitive experience (or 'stress') experienced by men when they either do not meet the masculine ideals of a society/group or when they have acted in the socalled feminine ways as were appropriate for the situation (Jurkovic \& Walker 2006:29; cf. Eisler 1995). Research conducted by Hassan (1995) revealed that men tend to experience MGRS around five specific areas of their lives, judged as masculine ideals (Jurkovic \& Walker 2006:29): (1) physical inadequacy, (2) emotional inexpressiveness, (3) subordination to women, (4) intellectual inferiority and (5) performance failure.

Jurkovic and Walker (2006:29) add that global modernisation and the emancipation of women in both home and workplace might add negatively to the stress experienced:

It can then be stated unequivocally that men are socialised into behaving in specific ways that a specific society deems acceptable, and favourable. In fact, all genders are socialised in this manner, thereby creating the marginalisation that people of different sexualities and genders experience when they do not conform to the status quo. It is postulated, however, that the abovementioned stress experienced by men might be specifically detrimental to the health of men (cf. Fragoso \& Kashubeck 2000); and it is well known that pressure experienced by men to act in more masculine ways and less feminine ways might lead to abusive behaviour towards women and children in an attempt to reassert their masculinity. What is less known, however, is that MGRS might lead to men having lower self-esteem and higher anxiety (Sharpe \& Heppner 1991); higher levels of anger and substance use (Blazina \& Watkins 1996); a higher level of depression (Cournoyer \& Mahalik 1995) and sexual aggression against women (Jurkovic \& Walker 2006:30; Rando, Rogers \& Brittan-Powel 1998).

The above-mentioned results of MGRS might add to the already high levels of anger and hostility experienced by men, which might lead to higher blood pressure and therefore higher risks of unhealthy living styles (cf. Eisler, Skidmore \& Ward 1988; Watkins et al. 1991). The accumulated psychosocial and physical consequences of MGRS ultimately place men at higher risk of committing suicide (Jurkovic \& Walker 2006:30; cf. Kidd 2002; Tacey 2000), mitigated by the fact that the hegemonic masculinity created by this discourse reduces their chances of seeking psychological (or spiritual) help (cf. Connell 1996) out of the fear that they would be seen as 'weak' or feminine (Jurkovic \& Walker 2006:30).

In direct contrast with the negative effects of strict masculine socialisation are the positive physical and mental health effects of religiosity and subsequent spiritual well-being. Religiosity and spirituality might be able to prevent the onset of both mental and physical illness (Koenig 1998), whilst certain religious practices might reduce the risk of substance use and abuse (cf. Gorsuch 1995), depression (Kennedy 1998; Koenig 1998), anxiety (Thorson 1998) and suicide (Jurkovic \& Walker 2006:30; cf. Gartner, Larson \& Allen 1991). It has been found that religious people are more satisfied with life and handle daily living and life-cycle stress and trauma in a better way (Jurkovic \& Walker 2006:30; cf. Maton 1989; Pargament \& Brant 1998).

As traditional masculine socialisation has been associated with negative mental and physical outcomes for men, and because maintaining an active and satisfying religious or spiritual life has opposite effects on men's health, it is postulated that religion plays an important role in the healthy development of a male gender identity, and the subsequent outcomes of a healthy gender identity in relation to a satisfying spiritual life. The opposite, however, is also true. It may be (in fact, it is postulated that this might be the case) that traditional patriarchal religious doctrines, theologies and practices might just be the fore behind the discourses that inform a specific hegemonic gender identity. It may also be that men are encouraged to engage in the so-called extrinsic religious behaviour (as to gain personal and social favour) and are less encouraged to engage in intrinsic religious behaviour as it might be seen as a more feminine way of being religious or spiritual.

Subsequently Mahalik and Lagan (2001:24) investigated the extent to which men internalise religious and spiritual experiences in the United States, and found that men indeed 
constrain themselves from religious activities which may be regarded as feminine, thereby supporting the gender-role conflict and stress theory. Their study revealed a significant relationship between the gender-role conflict and stress instruments (cf. Jurkovic \& Walker 2006:31), and these instruments assessing religiousness and spiritual well-being emphasise the power of gender discourses in a society and its effects on the general well-being of people. A study conducted by Jurkovic and Walker in 2006 with Australian men supports the notion that traditional male gender identity is more associated with an extrinsic orientation to religion if at all, and that many men idealise the traditional notion of masculinity in an attempt to avoid appearing too feminine (cf. Jurkovic \& Walker 2006:39; Levant \& Pollack 1995). Unfortunately, Zock (1997) has found that these behaviours might restrict men's opportunities to develop an intrinsic orientation towards religion, which, in turn, rob them from the opportunities to lead a fulfilling spiritual life to increase the quality of their both physical and mental health (Jurkovic \& Walker 2006:39). Conversely, however, this theory positively relates to the notion that socialisation aimed at a balanced development of both masculine and feminine qualities might result in men who are open to connect intrinsically with religion, thereby increasing their spiritual well-being (cf. Jurkovic \& Walker 2006:39; see studies conducted by Thompson 1991).

It is therefore apparent that an investigation into the relationship between religion or spirituality and masculinity in South Africa is of utmost importance not only because relationships between the genders are negatively affected but also because men's mental and physical health are directly affected by their level of religious satisfaction. Of utmost importance in this study is the possibility that religious practices could be transformed to assist in the development of equal and satisfying relationships between men and women in both familial and work context. However, before transformation could be supported, a thorough understanding of the relationship between the concepts of religion/spirituality and masculinity in the South African context should be carried.

Jurkovic and Walker (2006:40) rightly assert that the discipline of psychology should recognise that religion and spirituality are important dimensions of human development and intersect with other factors, such as gender, in the development of an identity. In turn, the discipline of religious studies should acknowledge the influence of religious doctrines and theologies on the construction of gender identity. Churches established upon doctrines and theologies should become accountable for the influence of their sermons and pastoral care on the development of gender identities, which operate mainly in the familial domain, and could either have dire consequences or could enrich family and work life so that congregants could live fulfilling and satisfied lives outside the church, albeit influenced by the church. These socially constructed identities operate on different levels and in different forms in the social context and therefore might have dire effects on the social justice that people experience. The first step in creating a more just and equal society is to recognise that men have the right to develop a masculine identity that embraces a wide range of characteristics, albeit socially constructed notions of masculinity and femininity, with the aim to live a full and satisfying life with an identity that embraces life and the Creator of this life in all its forms. As Jurkovic and Walker (2006) affirmatively state:

A nonharmful action in redefining masculine roles would be to discard the pressures for men to exhibit high-risk behavior in order to be accepted as men. The boundaries of maleness need to be widened to include views that are presently considered feminine - that it is okay to show emotion, to talk about feelings, to be religious/spiritual. (p. 40)

\section{Religion, spirituality and gender in Africa}

According to Chitando (2013:663), since the 1960s, African male scholars have played an integral role in the shaping of religious studies in Africa since the departure of European (male) scholars from Africa. Despite this influence, male African scholars neglected the influence of patriarchy and gender on the experience of religion, and the influence of a patriarchal religion on the lives of both men and women. African scholars tend to be oblivious to the differences in the experience of religion of different genders. A huge influence on the development and understanding of religion as experienced by gender has been the so-called 'Circle of Concerned African Women', who has ensured that gender and gender experiences are addressed in the studies of religion in Africa (cf. Chitando 2013:663-664). The Circle highlights the fact that inequitable gender relations in Africa are driven by a patriarchal religion and culture in Africa.

An unfortunate result of the increased work by the Circle in advocating women's rights in religion in Africa is that the voice of men was eradicated from discourses on gender (Chitando 2013:664), and male experiences of religion and spirituality in Africa have become almost non-existing. Therefore, although much is known regarding female experiences of patriarchal religion and the manner in which they suffer under 'the Word of God' as interpreted by male agenda, very little is known regarding men's experiences of religion and spirituality, and whether they have any insight into the development of their identity as influenced by religious doctrines and theologies. Any African woman is well aware of the influence of religion on family and gender roles and responsibilities - but the consequences of this have been never addressed adequately.

With the advent of HIV pandemic in Africa, interest into the discourse on gender in general, and the influence of masculinities and religion on the spread of this disease in specific has increased. More specifically, scholars have started to recognise that the social construction of masculinities might have an influence on response to HIV pandemic. As a result, scholars concluded that the general society, and 
specific communities (such as religious community), might influence the discourses around what it means to be a man in Africa, and what is expected from men to be regarded as 'real men' (cf. Chitando 2013:665). An additional reason behind the newfound interest in African masculinities is that men seem to be predominantly responsible for gender-based domestic violence.

In accordance with a social constructionist notion of masculinities, African scholars recognise that there is no single way of being male or masculine, also with reference to culture and religion. African scholars recognise that religion and subsequent spiritualties have an immense influence on the construction of masculinities, as is evident from the expectations of men, inherent in the dogma of the three dominant religions of Africa: African Traditional Religion, Christianity and Islam. These religions construct masculinities in such a manner that men are expected to be the leaders of the household (women and children), therefore projecting men as having dominion over women. In response to the aggressive masculinities that these expectations have created in Africa, African activists have contended that religious dogma supports the discourse of male authority, and that it has resulted in the justification of 'disciplining' women in the name of scripture. If women resist the abuse of such power, then this often results in domestic violence (Chitando 2013:665).

The history of Africa also has an immense influence on the construction of masculinities, with specific reference to black masculinities. The process of colonisation, urbanisation and Christianisation influenced the manner in which masculinities were, and are still, expressed (cf. Chitando 2013:665). During the 'battle of masculinity', black men defended their own masculinity against the dominion of European masculinities, resulting in a type of hegemonic masculinity in Africa, where women are often the victims of these attempts to reassert their own masculine authority. Additionally, increase in the loss of jobs and subsequent poverty undermine the authority of the so-called 'breadwinner' (dominant discourse in the masculine narrative), thereby resulting in the threatening of one's true masculinity. Nairobi (2008:21) emphasises how this 'battle of masculinities' has resulted in European masculinities demonising African ethnic masculinities. Instead of asserting a black African masculinity in its own right, many African masculinities have cross-pollinised with European masculinities, resulting in a hybrid masculinity between indigenous and western modernity. This ambiguity, according to Nairobi (2008:21), results in the assertion of power over and against those of femininity, at times with dire consequences. According to Magezi (2016:5), the solution is not, however, to romanticise African traditional culture and ideology (cf. Bowers 2009:102), which historically entails dominion over women and children as well, but to rather look critically at the challenges posed by both African modernity and technology and African tradition (cf. Magezi 2010). The goal should not be solely to create a unique African gender identity in opposition to the western hegemonic identity at the expense of equal gender relations. Instead, scholarship should engage in critical analysis of contemporary African challenges influenced by coloniality so that the disillusionment of people who experience daily disorder, injustices and oppression could be addressed adequately (Magezi 2016:4).

\section{Concluding with a post-foundational notion of practical theology in investigating the relationship between religion/spirituality and masculinities}

This research project, therefore, aims to adequately investigate the nature of the relationship between socially constructed masculinities in South Africa and religious and spiritual experiences, practices, dogmas and theologies, as is true for a post-foundational notion of practical theology. A postfoundational notion of practical theology firstly aims to listen to and describe in-context experiences (Meyer 2014), thereby acknowledging the influence of:

[C]ontextuality, the role of interpreted experiences and the influence of disciplinary tradition in the values people hold and how these values are used to reflect upon God and his presence in the world (cf. Müller 2005:76-77). (pp. 3-4)

This research recognises that religion and subsequent spiritualities could influence the manner in which masculinities in South Africa are constructed post-apartheid and postcolonial, and that ecclesial theologies and dogmas have immense power in informing gender and how people are men and women in this world. Chitando (2013:665-667) encourages the interrogation of the '... African appropriation of sacred texts in Christianity and Islam, as well as the use of oral traditions to support patriarchal dominance'. Similarly, Raines and Maguire (2001:1-13) advocate for the deconstruction and re-interpretation of sacred texts concerning masculinities in our aim of social justice and gender equality, thereby discovering the 'positive resources from world religions'.

The distribution of these two inventories, therefore, is aimed at increasing our awareness of this research's epistemic duty to move beyond the boundedness of practical theology as a discipline, our specific privileged communities, cultures and so forth, as to engage in a reflective and effective interdisciplinary discussion whichenhances our understanding of this phenomenon (cf. Meyer 2014:3-4; Müller 2005:76-77; Van Huyssteen 1999). Chitando (2013:667) supports this movement in the justification of the move towards Africanisation, where masculinities and religion as a theme should be placed right in the centre of the study of religion and spirituality in Africa as to adequately describe the 'lived realities of Africans' as the only vehicle for transformation.

After a proper description and understanding of the correlation between religion/spirituality and masculinities, the notion of 
transversality is utilised in creating a platform whereupon reflection could take place from the perspective of different reasoning strategies, understandings and experiences, as to keep the research endeavour concrete, local and contextual (cf. Meyer 2014:3-4; Müller 2005:77; Schrag 1992:148ff.; Welsch 1998:764ff.).

Such a notion towards practical theology emphasises both theological and practical considerations of a practical theological endeavour, which remains concerned with the living experiences of people as evident through 'their daily communications and relations within a specific cultural and social setting' (Gerkin1991:13; Meyer 2014:2). This research then underscores the importance of practical theology to remain propelled by elements of liberation, justice and reinstating human dignity (Meyer 2014:2).

Similarly, Miller-McLemore (2005:102-103) argues for a pastoral theology that incorporates aspects of a public theology, refocussing on the care of communities. Accordingly, such a pastoral theology focusses on a systematic criticism of all cultural norms and practices (cf. Koppel 2015) in terms of how it contributes to social injustices. Within this framework, the 'competiveness' of world views fades, whilst both their strengths and weaknesses are illuminated for the benefit of social and individual justice. In line with this, Magezi (2016:7) suggests that a pastoral theology for Africa from Africa should engage with '... contextual challenges and critically reflect on its theory as well as its contribution to global care rather than be narrowly focused'. This research project aligns itself with these values.

\section{Acknowledgements \\ Competing interests}

The author declares that no competing interests exist.

\section{Author(s) contributions}

I declare that I am the sole author of this research article.

\section{Ethical consideration}

This article followed all ethical standards for a research without direct contact with human or animal subjects.'

\section{Funding information}

This research received no specific grant from any funding agency in the public, commercial or not-for-profit sectors.

\section{Data availability statement}

Data sharing is not applicable to this article as no new data were created or analysed in this study.

\section{Disclaimer}

The views and the opinions expressed in this article are those of the author and do not necessarily reflect the official policy or position of any affiliated agency of the author.

\section{References}

Adams, C.J. \& Fortune, M.M. (eds.), 1995, Violence against women and children: A Christian theological sourcebook, Continuum, New York.

Allport, G. \& Ross, J.M., 1967, 'Personal religious orientation and prejudice', Journal of Personality and Social Psychology 5(4), 432-443. https://doi.org/10.1037/h0021212

Allport, G.W., 1950, The individual and his religion: A psychological interpretation, Macmillan, Oxford.

Argyle, M. \& Beit-Hallahmi, B., 1975, The social psychology of religion, Routledge, London.

Armstrong, T. \& Crowther, M., 2002, 'Spirituality among older African Americans', Journal of Adult Development 9(1), 3-12.

Bachman, R., 1994, Violence against women: A national crime victimization survey report, US Department of Justice, MI.

Bell, C.C. \& Mattis, J., 2000, 'The importance of cultural competence in ministering to African American victims of domestic violence', Violence against Women 6(5), 515-532. https://doi.org/10.1177/10778010022182001

Bent-Goodley, T.B. \& Fowler, D.N., 2006, 'Spiritual and religious abuse: Expanding what is known about domestic violence', Journal of Women and Social Work 21(3), 282-295. https://doi.org/10.1177/0886109906288901

Blazina, C. \& Watkins, C.E., 1996, 'Masculine gender role conflict: Effects on college men's psychological well-being, chemical substance use, and attitudes toward help-seeking', Journal of Counseling Psychology 43(4), 461-465. https://doi. org/10.1037/0022-0167.43.4.461

Bowers, P., 2009, 'Christian intellectual responsibilities in modern Africa', Africa Journal of Evangelical Theology 28(2), 91-114.

Chitando, E., 2013, 'Religion and masculinities in Africa: An opportunity in Africanization', in I.A. Phiri \& D. Werner (eds.), Handbook of theological education in Africa, pp. 662-670, Regnum Books International, Oxford, viewed 29 Augus 2017, from https://www.google.com/url?sa=tandrct=jandq=andesrc=sandsource = webandcd $=2$ andcad $=$ rjaanduact $=8$ andved $=2$ ahUKEwj_-Ov2htDjAhWRDOwKHcx NDswQFjABegQIABACandurl=http $\% 3 \mathrm{~A} \% 2 \mathrm{~F} \% 2 \mathrm{Fwww}$.ocms.ac.uk $\% 2$ Fregnum $\% 2$ Fdownloads\%2FHandbook of Theological Education in_Africa-Watermarked. pdfandusg=AOvVawOuD2trnTHËeGHX97zU8ykm.

Connell, R.W., 1996, Masculinities, Allen and Unwin, Sydney

Constantinople, A., 1973, 'Masculinity-femininity: An exception to a famous dictum?', Psychological Bulletin 80(5), 389-407. https://doi.org/10.1037/h0035334

Cournoyer, R.J. \& Mahalik, J.R., 1995, 'Cross-sectional study of gender role conflict examining college-aged and middle-aged men', Journal of Counseling Psychology 42(1), 11-19. https://doi.org/10.1037/0022-0167.42.1.11

DeVaus, D. \& McAllister, I., 1987, 'Gender differences in religion: A test of the structural location theory', American Sociological Review 52(4), 472-481. https:// doi.org/10.2307/2095292

Eisler, R.M., 1995, 'The relationship between masculine gender role stress and men's health risk: The validation of the construct', in R.F. Levant \& W.S. Pollack (eds.), $A$ new psychology of men, pp. 207-225, Basic Books, New York.

Eisler, R.M., Skidmore, J.R. \& Ward, C.H., 1988, 'Masculine gender stress: Predictor of anger, anxiety, and health-risk behaviors', Journal of Personality Assessment 52(1) 133-141. https://doi.org/10.1207/s15327752jpa5201_12

Ekhardt, B.N. \& Goldsmith, W.M., 1984, 'Personality factors of men and women pastoral candidates: Part 1. Motivational profile', Journal of Psychology and Theology 12(2), 109-118. https://doi.org/10.1177/009164718401200204

Erikson, E.H., 1958, Young man Luther: A study in psychoanalysis and history, Norton, New York.

Erikson, E.H., 1969, Gandhi's truth. On the origin of militant non-violence, Norton, New York.

Fetzer Institute, 1999, Multidimensional measurement of religiousness/spirituality for use in health research, John E. Fetzer Institute, Kalamazoo, MI.

Fragoso, J.M. \& Kashubeck, S., 2000, 'Machismo, gender role conflict, and mental health in Mexican American men', Psychology of Men and Masculinity 1(2) 87-97. https://doi.org/10.1037/1524-9220.1.2.87

Francis, L.J., 1991, 'The personality characteristics of Anglican ordinands: Feminine men and masculine women?', Personality and Individual Differences 12(1) 1133-1140. https://doi.org/10.1016/0191-8869(91)90076-N

Francis, L.J. \& Wilcox, C., 1996, 'Religion and gender orientation', Personality and Individual Differences 20(1), 119-121. https://doi.org/10.1016/0191-8869(95)00135-S

Gartner, J., Larson, D.B. \& Allen, G., 1991, 'Religious commitment and mental health A review of the empirical literature', Journal of Psychology and Theology 19(1) A review of the empirical literature', Journal of Psychol

Gerkin, C.V., 1991, Prophetic pastoral practice, Abingdon Press, Nashville, TN.

Gorsuch, R.L., 1995, 'Religious aspects of substance abuse and recovery', Journal of Social Issues 51(2), 65-83. https://doi.org/10.1111/j.1540-4560.1995.tb01324.x

Gorsuch, R.L. \& McPherson, S.E., 1989, 'Intrinsic/extrinsic measurement: I/E-revised and single-item scales', Journal for the Scientific Study of Religion 28(3), 348-354. https://doi.org/10.2307/1386745

Hassan, R., 1995, Suicide explained: The Australian experience, Melbourne University Press, Melbourne.

Hill, P.C. \& Maltby, L.E., 2009, 'Measuring religiousness and spirituality: Issues, existing measures, and the implications for education and wellbeing', in M. De Souza, L.J. Francis, J. O'Higgins-Norman \& D.G. Scott (eds.), International handbook of education for spirituality, care and wellbeing, International Handbooks of Religion and Education (series 3), pp. 33-50, Springer. 
Hoge, D.R., 1972, 'A validated intrinsic religious motivation scale', Journal for the Scientific Study of Religion 11(4), 369-376. https://doi.org/10.2307/1384677

Hunt, R.A. \& King, M.B., 1971, 'The intrinsic-extrinsic concept: A review and evaluation', Journal for the Scientific Study of Religion 10(4), 339-356. https://doi. org $/ 10.2307 / 1384780$

Judd, M.W., 2009, 'Religious orientation, context effects, and socially desirable responding', Master of Arts thesis, Department of Psychology, Marietta College, Marietta, $\mathrm{OH}$

Jurkovic, D. \& Walker, G.A., 2006, 'Examining masculine gender-role conflict and stress in relation to religious orientation and spiritual well-being in Australian men', The Journal of Men's Studies 14(1), 27-46. https://doi.org/10.3149/jms.1401.27

Kennedy, G.J., 1998, 'Religion and depression', in H.G. Koenig (ed.), Handbook of religion and mental health, pp. 128-146, Academic Press, New York.

Kidd, M., 2002, 'Suicide and manhood', Manhood online, viewed 20 January 2018 from http://www.manhood.com.au/scripts/manhood.

King, J.E. \& Crowther, M.R., 2004, 'The measurement of religiosity and spirituality: Examples and issues from psychology', Journal of Organizational Change Management 17(1), 83-101. https://doi.org/10.1108/09534810410511314

Koenig, H.G., 1998, Handbook of religion and mental health, Academic Press, New York.

Koenig, H.G., McCullough, M. \& Larson, D.B., 2000, Handbook of religion and health Oxford University Press, New York.

Koppel, M.S., 2015, 'Practicing public pastoral theologies in contexts of difference', Journal of Pastoral Theology 25(3), 151-152. https://doi.org/10.1080/10649867. 2015.1123923

Levant, R.F. \& Pollack, W.S., 1995, The new psychology of men, Basic Books, New York.

Levant, R.F., Richmond, K., Cook, S., House, A.T. \& Aupont, M., 2007, 'The femininity ideology scale: Factor structure, reliability, convergent and discriminant validity, and social contextual variation', Sex Roles 57(5-6), 373-383. https://doi. org/10.1007/s11199-007-9258-5

Luyt, R., 2005, 'The male attitude norms inventory-II; A measure of masculinity ideology in South Africa', Men and Masculinities 8(2), 208-229. https://doi. org/10.1177/1097184X04264631

Luyt, R., 2015, 'Beyond traditional understanding of gender measurement: The gender (re)presentation approach', Journal of Gender Studies 24(2), 207-226, viewed 20 February 2018, from https://www.tandfonline.com/doi/abs/10.1080/ 09589236.2013 .824378$.

Luyt, R., 2017, 'Masculinities representations inventory (MRI, English version) A measure of gender (re)presentation', Journal of Men's Studies 1-27 viewed 20 February 2018, 26(2), from https://journals.sagepub.com/doi/10.1177/ 1060826517736781.

Magezi, V., 2010, Pastoral care in tension between tradition and modernity: Pastoral ministry and biblical response to challenges of fear of death, fear of spirits and hospitality in Africa, Lambert Academic, Saarbrücken.

Magezi, V., 2016, 'Reflection on pastoral care in Africa: Towards discerning emerging pragmatic pastoral ministerial responses', In die Skriflig 50(1), a2130. https://doi. org/10.4102/ids.v50i1.2130

Mahalik, J.R. \& Lagan, H.D., 2001, 'Examining masculine gender role conflict and stress in relation to religious orientation and spiritual well-being', Psychology of Men and Masculinity 2(1), 2-33. https://doi.org/10.1037/1524-9220.2.1.24

Maluleke, R., 2018, Crime against women in South Africa: An in-depth analysis of the victims of crime survey data, Crime Statistics Series, Vol. V, Statistics South Africa, Pretoria.

Maton, K.I., 1989, 'The stress-buffering role of spiritual support: Cross-sectional and prospective investigations', Journal for the Scientific Study of Religion 28(3), 310-323. https://doi.org/10.2307/1386742

McClure, J.S. \& Ramsay, N.J. (eds.), 1998, Preaching about sexual and domestic violence: Telling the truth, United Church Press, Cleveland, $\mathrm{OH}$

Meyer, J., 2014, 'Development of alternative interpretations: The story of an orphaned boy affected by HIV and AIDS and father abandonment', Verbum et Ecclesia 35(2), Art. \#884, 13 p. https://doi.org/10.4102/ve.v35i2.884

Miller-McLemore, B.J., 2005, 'Pastoral theology and public theology', in E. Graham \& A. Rowlands (eds.), Pathways to the public square, pp. 95-106, Transaction, London.

Müller, J.C., 2005, 'A post-foundationalist, HIV-positive practical theology', Practical Theology in South Africa 20(2), 72-88.

Nairobi, K., 2008, 'Men for the equality of men and women', in T. Njoya (ed.), The crisis of explosive masculinity, p. 21, MEW, Nairobi.
Neighbors, H.W., Musick, M.A. \& Williams, D.R., 1998, 'The African-American minister as a source of help for serious personal crises: Bridge or barrier to mental health care?', Health Education and Behavior 25(6), 759-778. https://doi. care?', Health Education and

'Neil, J.M., 1981, 'Male sex-role conflicts, sexism, and masculinity: Psychological implications for men, women, and the counselling psychologist', The Counseling Psychologist 9(2), 61-81. https://doi.org/10.1177/001100008100900213

O'Neil, J.M., 1982, 'Gender role conflict and strain in men's lives: Implications for psychiatrists, psychologists, and other human-service providers', in K. Solomon \& N.B. Levy (eds.), Men in transition: Theory and therapy, pp. 5-49, Plenum, New York.

O'Neil, J.M., 1990, 'Assessing men's gender role conflict', in D. Moore \& F. Leafgren (eds.), Problem solving strategies and interventions for men in conflict, pp. 23-38, American Counseling Association, Alexandria, VA.

Paloma, M.M. \& Gallup, G.H., 1991, Varieties of prayer: A survey report, Trinity Press, Philadelphia, PA.

Pargament, K.I. \& Brant, C.R., 1998, 'Religion and coping', in H.G. Koenig (ed.) Handbook of religion and mental health, pp. 111-128, Academic Press, New York.

Pleck, J.H., 1981, The myth of masculinity, MIT Press, Cambridge.

Pleck, J.H., 1995, 'The gender role strain paradigm: An update', in R.F. Levant \& W.S Pollack (eds.), A new psychology of men, pp. 11-32, Basic Books, New York.

Raines, J.C. \& Maguire, D.C., 2001, What men owe to women: Men's voices from world religions, SUNY Press, Albany, NY.

Raj, A. \& Silverman, J., 2002, 'Violence against immigrant women: The roles of culture, context, and legal immigrant status on intimate partner violence', Violence against Women 8(3), 367-398. https://doi.org/10.1177/10778010222183107

Rando, R.A., Rogers, J.R. \& Brittan-Powell, C.S., 1998, 'Gender role conflict and college men's sexually aggressive attitudes and behavior', Journal of Mental Health Counseling 20, 359-369.

Sanders, C.J. (ed.), 1995, Living the intersection: Womanism and Afrocentrism in theology, Fortress Books, Minneapolis, MN

Schrag, C.O., 1992, The resources of rationality: A response to the postmodern challenge, Indiana University Press, Bloomington, IN.

Statistics South Africa, 2016, General household survey 2015, statistical release (P0318), Statistics South Africa, Pretoria, viewed 08 March 2019, from https:// www.statssa.gov.za/publications/P0318/P03182015.pdf.

Tacey, D., 2000, Re-enchantment: The new Australian spirituality, Harper Collins, Sydney.

Thompson, E.H., 1991, 'Beneath the status characteristics: Gender variation in religiousness', Journal for the Scientific Study of Religion 30(4), 381-394. https:// doi.org/10.2307/1387275

Thompson, E.H. \& Pleck, J.H., 1986, 'The structure of the male role norms', American Behavioural Scientist 29(5), 531-543. https://doi.org/10.1177/ 000276486029005003

Thorson, J.A., 1998, 'Religion and anxiety: Which anxiety? Which religion?', in H.G. Koenig (ed.), Handbook of religion and mental health, pp. 147-160, Academic Press, New York.

Van Huyssteen, J.W., 1999, The shaping of rationality: Towards interdisciplinarity in theology and science, Eerdmans, Grand Rapids, MI.

Watkins, P.L., Eisler, R.M., Carpenter, L., Schechtman, K.B. \& Fisher, E.B., 1991, 'Psychosocial and physiological correlates of male gender role stress among employed adults', Behavioral Medicine 17(2), 86-90. https://doi.org/10.1080/08 964289.1991.9935163

Welsch, R.L., 1998, An American anthropologist in Melanesia: A.B. Lewis and the Joseph N. Field expedition, 1909-1913, 2 vols., University of Hawaii Press, Honolulu.

West, T.C., 1999, Wounds of the spirit: Black women, violence, and resistance ethics, New York University Press, New York.

Wolff, D.A., Burleigh, D., Tripp, M. \& Gadomski, A., 2001, 'Training clergy: The role of the faith community in domestic violence prevention', Journal of Religion and Abuse 2(4), 47-62. https://doi.org/10.1300/J154v02n04_04

Zock, H., 1997, 'The predominance of the feminine sexual mode in religion: Erikson's contribution to the sex and gender debate in the psychology of religion' International Journal for the Psychology of Religion 7(3), 187-198. https://doi. org/10.1207/s15327582ijpr0703_7 